\section{Charting the decline}

SIR-The letter from J.F. Lamb ${ }^{1}$ has prompted us to examine some data extracted from a recently published study $^{2}$. Table 1 shows country-by-country mean citation rates of papers published in Nature during 1981-85 as related to the mean citation rate of all papers published in Nature in the same period. All countries publishing more than ten papers are shown.

\begin{tabular}{llll}
\hline \multicolumn{3}{c}{ TABLE 1 Relative $\begin{array}{c}\text { Citation Rate (RCR) of papers } \\
\text { in Nature }\end{array}$} & \\
\cline { 1 - 3 } \multicolumn{1}{c}{ Country } & RCR & \multicolumn{1}{c}{ Country } & RCR \\
Sweden & & & \\
Switzerland & 1.92 & Poland & 0.70 \\
Japan & 1.78 & Italy & 0.67 \\
USA & 1.46 & Austria & 0.67 \\
West Germany & 1.18 & Norway & 0.64 \\
Denmark & 1.17 & Canada & 0.62 \\
Israel & 1.07 & USSR & 0.52 \\
The Netherlands & 1.05 & Australia & 0.46 \\
France & 1.01 & Spain & 0.46 \\
Belgium & 0.92 & Brazil & 0.41 \\
United Kingdom & 0.79 & New Zealand & 0.41 \\
Hungary & $\mathbf{0 . 7 7}$ & Ireland & 0.35 \\
Finland & 0.75 & South Africa & 0.23 \\
& 0.70 & India & 0.14 \\
\hline
\end{tabular}

The relative citation rate ( $R C R$ ) has a value greater than 1.00 when the papers of the country in question are cited above the journal's average and conversely. Nature published 8,043 papers in $1981-85$ with an average citation rate of 16.63 .

As can be seen, Sweden heads the ranking, followed by Switzerland, Japan, the United States and West Germany. The United Kingdom is ranked eleventh. This could be considered to be in line with the reports of Lamb and others on the decline of British science ${ }^{3,4}$ although other studies did not find any statistically significant decline in the indicators of British science during the $1980 \mathrm{~s}^{5-8}$. For that reason, we consider the whole problem of the decline of British science is still open to discussion - leaving aside questions such as what is meant by decline ${ }^{9}$ and whether whatever it is is correlated with the decline in funding, for example.

Accordingly, we have repeated the same exercise with another 'high quality'

\begin{tabular}{|c|c|c|c|}
\hline Country & RCR & Country & RCR \\
\hline United Kingdom & 1.22 & Norway & 0.80 \\
\hline Sweden & 1.21 & Canada & 0.79 \\
\hline Switzerland & 1.16 & France & 0.79 \\
\hline Belgium & 1.12 & Spain & 0.79 \\
\hline Denmark & 0.92 & Austria & 0.79 \\
\hline The Netherlands & 0.92 & Hungary & 0.74 \\
\hline South Africa & 0.90 & Ireland & 0.67 \\
\hline West Germany & 0.89 & Finland & 0.66 \\
\hline USA & 0.89 & Poland & 0.64 \\
\hline Australia & 0.87 & Argentina & 0.63 \\
\hline Israel & 0.82 & USSR & 0.49 \\
\hline Japan & 0.81 & India & 0.41 \\
\hline New Zealand & 0.80 & Chile & 0.25 \\
\hline
\end{tabular}

periodical, the Biochemical Journal.

Table 2 presents the results, covering 4,475 papers published in $1981-85$, with an average citation rate per paper of 6.90 . As will be seen, the United Kingdom is ranked in first position.

Our sole purpose here is to suggest that a counting such as that of Lamb is not by itself a sufficient measure of decline.

Bibliometric methods are not the most serviceable tools unequivocally to prove such a decline during the $1980 \mathrm{~s}$. A more realistic approach would show ${ }^{2}$ that British science, like science in other countries, is in decline in some fields and on an upward move in others.

Moreover, in any population of papers, the distribution according to quality (citation rate is but a proxy) is highly skewed. Our investigations ${ }^{2}$ indicate that probably the most important factor in improving scientific performance of a country is finding a way to raise the quality and not quantity of the publications by influencing the skew distribution to have a low quality 'tail' as short as possible.

\section{Institute of Inorganic and}

T. BRAUN

Analytical Chemistry,

L. Eötvös University, POB 123,

1443 Budapest, Hungary

A. SCHUBERT

Information Science and Scientometrics Research Unit (ISSRU),

Library of the Hungarian

Academy of Sciences,

$P O B$ 7, 1361 Budapest, Hungary

1. Lamb, J.F. Nature 343, 404 (1990)

2. Schubert, A., Glänzel \& W. Braun, T. Scientometrics 16 , 3 (1989).

3. Irvine, J., Martin, B., Peanock, T. \& Turner, R. Nature 316, 587 (1985)

4. Martin, B.R., Invine, J., Narin, F. \& Sterritt, C. Nature $\mathbf{3 3 0}$, 123 (1987).

5. Leydesdorff, L. Science and Public Policy 15, 270 (1988)

6. Nederhof, J. Scientometrics 14, 475 (1988).

Braun, T., Glänzel, W. \& Schubert, A. Scientometrics 15 165 (1989).

8. Braun, T., Glänzel, W. \& Schubert, A. The Evaluation of Scientific Research, Ciba Foundation Conference, p. 32 (Wiley, Chichester, 1989).

9. Nye, M.J. ISIS, 75, 697 (1984)

10. Babbage, Ch. Nature 340, 499 (1989).

\section{Growing dissent}

SIR - The debate between advocates of sustainable economics and pro-growth economics is more complicated than implied by the recent leading article, "Doctrinal fallacies of stewardship" (Nature 344, 179; 1990).

(1) The assumption that funding for scientific research and development entails economic growth cannot be cogently defended. While we agree that scientific enquiry is at present underfunded, both in Britain and elsewhere, the explanation cannot be attributed to any single factor.
(2) Clearly the term 'economic growth' has a ceremonial value, while "no-growth lobby' has a pejorative ring. Yet even radical 'greens' are in favour of 'economic growth': the issue is what kind of growth. The article begs several questions. Just what, for example, do the national income accounts at present measure?

(3) While the article seems relatively sanguine about the future of European civilization, there is a remarkable inconsistency inherent in the assertion that Africa, "even before AIDS, seemed destined to be the first continent to be lost to human habitation through wayward mismanagement". Even assuming, out of ethnocentric arrogance if nothing else, that Africans bring the house down on their own heads, an ecological viewpoint forces recognition that our own selfinterest is at stake. Africa is part of the global ecosystem.

(4) No responsible scientist claims to be able to predict the future (unless all other conditions are equal), yet the essay skates perilously close to prophecy on more than one front. Chaos theory, if it means anything vis-à-vis the environmental policy debate, implies that small and seemingly insignificant variables can have major unpredicted effects. Clearly, some kinds of economic growth could have unpredicted and disastrous ecological effects. Furthermore, even assuming adequate funding for basic science research, there is no guarantee that the knowledge necessary to sustain civilization as we know it will be forthcoming.

(5) Finally, the article ignores a host of so-called science-society issues that such luminaries as Albert Einstein and Erwin Schrödinger have raised.

Rather than being the last word, we hope that the leading article serves the function of opening up and extending the conversation. Perhaps the wide range of articles dealing with various facets of ecology, environment and human impacts that have graced the pages of Nature are the beginning of a vital process of public deliberation informed by scientific inquiry.

Department of Philosophy

MAX OELSCHLAEGER

POB 13526,

University of North Texas,

Denton, Texas 76203, USA

\section{Missing woman}

SIR-Sachi Sri Kantha (Nature 344, 582; 1990 ) concludes that 21 women so far have been awarded the Nobel prize. However, at least one woman was missing. In 1909, the Swedish novelist Selma Lagerlöf was the first woman to receive the literature prize.

ÅKE STRID

CSIRO Division of Plant Industry, GPO Box 1600, Canberra ACT 2601 ,

Australia 